\title{
The Social Pedagogical Discourse of Modernity. The Politics of Human Rights and International Social Work
}

\author{
Christian Wevelsiep \\ EUF, University of Flensburg, Schleswig-Holstein, Bochum, Germany \\ FamilieWevelsiep@t-online.de
}

\section{Abstract}

The basic thesis of this paper is that the helping professions have an indispensable task: to reflect the constitution of society in the context of the perception of the other. This discourse of social pedagogy addresses the conditions under which we encounter each other and under which we recognize each other. It is to be asked to what extent this discourse of social pedagogy could contribute to open the horizons of the common, which have been closed by all conceivable forms of violence. The background of the discourse, mentioned here, is close to the social philosophical discourse of modernity. It reflects the form of modernity in all its moral, social and political dimensions. The social-philosophical reference to the present is accompanied by the indispensable critique of power. It designates stages of reflection of that critique that make possible a theory of society. It thus forms, which is to be shown as a result, the categorical framework of an analysis that enables a view of the structures of existing power relations. It thematizes the essential approaches to the practical overcoming of these phenomena. For this purpose, it will be reflected by way of introduction which theoretical reference the mentioned discourse has and how it is to be understood in comparison to other discourses - thus, it is first about the connections from social philosophy to social pedagogy (2). Within this framework, it will then be shown that the helping professions have an internal reference to the world, which is of eminent importance for the self-description of the discourse (3). How the language of human rights can be translated into transcultural perspectives of action is a complex question that is answered here from a fundamental anthropological perspective (4).

\section{Keywords}

social; pedagogical; discourse; ethics, inclusion, modernity,

integration

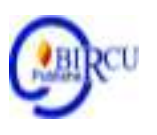

\section{Introduction}

To speak of signatures of our time is problematic. There is no single event or a grand iconic gesture that could claim to represent the whole. Nevertheless, there are objects in public space that give more than a discrete indication of the times in which one lives and the nature of the conflicts that exist between ways of life.

In Ghent, for example, there is a monument to Belgium's King Leopold II, a symbol of rule that, like many others, was to be overthrown in the summer of 2020. A bloodstained cloth covered the statue's face with the words: I can't breathe. It recalled the death of George Lloyd Floyd, which caused a wave of worldwide protests. The violence commemorated by the deconstruction of the bust, however, went further. It was directed against a past for which the word "reappraisal" can hardly stand. Leopold II had established a reign of terror in the Congo and was responsible for the deaths of millions of Congolese. 
The symbolic gesture of covering an object with the violence that others had to experience in their own bodies draws attention to the unresolved conflicts of our time - and to the unfulfilled promises that have been conveyed to us through the language of human rights. The colonial legacy weighs heavily; racism continues unabated; violence offers its face in all facets. In the irreconcilability the real signatures of our time are indicated.

The first impulse turns against this diagnosis. Against the conflict, we might think, the law of the modern institutions can be offered, against the arbitrary rule we "have" a morality at our disposal. Not the superficial harmony, but nevertheless the prospect of reconciliation counts to the same extent to the qualities of our time - so we would like to believe it. However, this is contradicted by the insight that modern societies have so far not been able to ensure the integration of the whole. And thus the question arises, to which social and societal authority one should turn to transform the conflict of life forms into livable conditions. To the existing law, which at least partially reflects our moral intuitions? To politics, which might be responsible for more than formal procedures, but for moral cohesion? Or even to that anonymous mechanism of social integration of functional systems emphasized by sociology?

All these instances have indeed played an essential part in the cohesion of society. But they have obviously not been able to prevent societies from being threatened by inequalities in the long run. Social anomie can once again become a real horror. And this negative insight cannot be mitigated by any prospect of a "higher" instance of reason. The following considerations take up this pessimistic finding; but they think beyond it. They are not under the sign of a superior instance, but under the sign of a particular discursivity. This discourse is "socio-pedagogical" and this means nothing else than that the existing conflicts between forms of life are thematized under certain social conditions.

The basic thesis is that the socio-pedagogical view cannot stand alone for cohesion, but that it has an indispensable task. Its task is to reflect on the constitution of society in the context of the perception of the Other. This discourse thus stands between the fundamental insights given to us by ethics, anthropology, and the human sciences. In a certain way, the discourse addresses the conditions under which we encounter each other and under which we recognize each other.

The suspicion that the horizon of the whole is broken is admittedly not eliminated here by social pedagogical knowledge. The question is rather to what extent this sociopedagogical discourse could contribute to opening the horizons of the common, which have been closed by all conceivable forms of violence.

For this purpose, the theoretical reference of the mentioned discourse and how it is to be understood in comparison to other discourses will be reflected upon in an introductory way - thus, it is first about the connections from social philosophy to social pedagogy (1). Within this framework, it will then be shown that the helping professions have an internal reference to the world, which is of eminent importance for the self-description of the discourse (2). How the language of human rights can be translated into transcultural perspectives of action is a complex question that is answered here from a fundamental anthropological perspective (3). 


\section{Review of Literatures}

\section{From Social Philosophy to Social Pedagogy}

The discourse mentioned above is, of course, particularly close to what can be called the social philosophical discourse of modernity. This reflects the form of modernity in all its moral, social and political dimensions (Honneth 1989). The social-philosophical reference to the present is accompanied by the indispensable critique of power. It designates stages of reflection of that critique that make possible a theory of society. It thus forms the categorical framework of an analysis that enables a view of the structures of existing power relations; at the same time, it thematizes approaches to the practical overcoming of these phenomena.

What, on the other hand, does the social pedagogical discourse mean here? Of course, it is also about the elementary things, about power, domination and selfempowerment. In contrast, the social and pedagogical orientation requires a certain degree of optimism. For here the human being moves into the center of reflection. And explicitly the conditions of being together are emphasized, which can be called worth living. It is thus the question of the human being in concrete relations that distinguishes this discourse from others. Thus, the phenomena of non-violence, solidarity, integration, human rights and difference move to the center. Only by relating these concepts to one another will one be able to comprehend the extent to which these categories form a substantial coherence.

For social psychologists such as Steven Pinker, modernity represents a discrete victory of humanity over its own weakness. Violence had unfolded in every conceivable situation and left a lasting mark on the stories of humanity, Pinker argues. A new chapter, meanwhile, has been written since peace was made possible not only on paper. This facet of the civilizing process is noteworthy because it has been accompanied by a de facto decline in violence -because, psychologically speaking, people have become less impulsive, unbridled, and prone to violence (Pinker 2013, p. 125). And also because most modern society has managed to tame the barbarians within.

This semantics is unusual, seemingly anachronistic. Barbaric, in this reading, are not the others who stand far from the bright center of a culture, but barbaric would have to be called man himself. Each generation, which has to be socialized, civilized and cultivated anew, pushes this procedure forward and is refined in subtle procedures of disciplining. Some call it education, enlightenment; others see in this process rather the efficacy of power (Wilson 1974; Wilson/Herrnstein 1985.) One can celebrate the education of the human race as the victory of the civilizing process. Or one may suggest that the skin of civilization is extremely thin and that violence, even within a culture, always remains dependent on certain factors (Welzer 2005; 2008).

However one sets the accents here: the reasonable content of morality is to be defended. It expresses itself in ways of self-understanding: equal respect for everyone and a general solidary responsibility for others. Without this minimal consensus of universalism, no social theoretical analysis is conceivable. The difficulties begin, of course, at the realization that this self-evident universalism quickly becomes the focus of criticism. Even a universalist ethos cannot hide the fact that we misjudge and disregard each other in many ways. Ruthless assimilation turns others into mere objects, or makes them disappear, as it were (Wilderson 2020).

Only a perspective in which the relational structure of the Other is given meaning leads further at this point. It would have to be brought together - and therein lies an essential core of "social pedagogy" - with a form of universalism that remains sensitive to all the dissonances of a human world. Thus, not the superficial affirmation of the 
sameness, but the difference-sensitive inclusion of the other becomes the decisive touchstone (Habermas 1996, pp. 11-65).

It is not the question at which point of moral development one stands in general. But rather under which conditions the inclusion of the other can succeed in complex societies, if it is to be more than lip service. High-quality research is available on this question.

The connection between democratic self-legislation and solidarity, for example, should be mentioned in this context (Brunkhorst 2002). Accordingly, stages of solidarity have emerged from the Christian postulate of fraternity, reaching as far as political legal cooperative.

Solidarity is not a luxury that prosperous societies can afford or not; nor is it merely a quality of a community whose members deal with each other in a certain way. Only in the broad horizon of globalization is the claim of democratically enabled solidarity properly understood. In the beginning, solidarity was bound to the political form of the nation-state, but later solidarity in the functionally differentiated society has developed globally. The massive problems that all societies and cultures face today will only be overcome if the solidarity potential of modern democratic societies is realized (Geiselberger 2017).

Furthermore, the socio-educational discourse of modernity is of course also characterized by an orientation towards modern achievements and values. Without the idea of human rights, which shape our consciousness as modern contemporaries, a social pedagogical discourse can hardly be conducted. Human rights have acquired the status of the sacred in modernity. That is, they go back to an affirmative genealogy. As is well known, the sacred in the religious sense made social cohesion possible in older societies; a modern interpretation of the sacred is quite comparable to this. Now, of course, it is secular values and fundamental rights that go hand in hand with subjective certainty, affective intensity, and a sense of evidence (Joas 2015).

But even this does not conclude the discourse meant here. Orientation to values and rights is, of course, unavoidable; but unresolved in this context is, after all, the equally important question of how normative orientations can have an impact and unfold in particular societies. The invocation of a valid core of fundamental rights is indispensable, but it is referred to a specific understanding of the world. The social-pedagogical discourse lastly touches upon the genuinely philosophical question of how the moral goal of a successful life can be thought together with the limits and conditions of a community. The discourse is thus located at an interface, or junction. Human existence is inescapably referred to community; but the conditions of that community are never substantively given, except perhaps in a rigorously metaphysical order. (Nancy 1988).

Communities create meaning. They enable the sharing of a communal store of signs and symbols. They create frameworks for actually human life, insofar as only here are language, understanding, moral norms, and mutual respect realized and embodied.

But there are multiple ways to realize these fundamental conditions and to transform them into a political form. This actually trivial insight makes a big difference whether one draws, for example, on liberal or communitarian rationales. The most difficult point of reference seems to be contained - even after decades of learned discussions - in the category of the "we".

A "we" provides cohesion and forms the prerequisite of our world relations. But this "we" is always threatened, by processes of closure and enemy construction, but also by the illusion of wanting to establish such a community by coercion. This is precisely what, philosophically understood, a community is not: a closed community into which nothing foreign can penetrate, a substance created by the will of the individuals or even an order in 
which something indestructible and unconditional would emerge. Rather, one speaks of the epistemic, existential and normative imperfection that is given to every community (Bonacker 2002).

It is this social theoretical humility that is so difficult to integrate into the selfunderstanding of the helping professions. Professions depend on a community in which respect for all is taken for granted. They need, as it were, domestical politics of justice and demand procedures of equal recognition. At the same time, they have to live with the insight that these normative expectations are only ever embedded in imperfect communities.

\section{Discussion}

\subsection{The World Reference of the Helping Professions}

Where does international social work stand in this context, since it is only one voice in a many-voiced concert? The critique of injustice in the world is at the center; the discipline functions as a representative of the excluded and forgotten - but it does not stand outside society. Only as a self-reflective discipline can it assume the responsibility of its mandate, which means recognizing its own limitations and positioning in the field of power.

This self-reflection is not comfortable. For it cannot be a matter of simply contrasting the perspective of the international dimension with that of conventional, local social work. Rather, transnational studies broaden the focus of the helping professions in the sense that they engage in border reflection.

In concrete terms, border work means: taking the point of view of the people concerned in their lifeworld and perceiving in it possible entanglements, ruptures and connections that do not allow for clear gains in identification. To put it more simply: the work with a "client" is embedded in legal, social, cultural and biographical contexts, which are not determined by any isolated connection. The post-modern way of life joins the origin and the region of arrival, the distant and the local, the new and the familiar relationships. Border work means: the legal and social tensions must be addressed, but they cannot be resolved from any conceivable location. The cultural contradictions and biographical patterns can not bei solved in an easy orientation. People in the spaces of transmigration have to live and survive with these conditions - but social work actors are also "exposed" to them. For they are part of the nation-state arrangement, part of the hegemonic structure of world society - as representatives of a social power complex.

The conditions under which people encounter each other in asymmetrical relations are also to be understood as reflexive. The social and political world is not well-ordered but, as it were, curved and unfinished. It is therefore necessary to counter idealistic thought with reflexive criticism.

In the 1990s, a discourse could unfold that was carried by an optimistic keynote: economic prosperity should sooner or later spread over all regions of the world (Albert/Stichweh 2007; Gosewinkel 2004). A global ethic moved into the vicinity that could minimize all regional conflicts and cultural tensions (Küng/Senghaas 2003). As is well known, this optimism had to do with the world political upheavals of the 1990s, the consequences of which are still being felt today. In this narrative, social work finds its place in the development discourse. It says that universal rights should be granted to everyone, as ethnic and cultural particular interests dissolve as soon as welfare regimes can unleash their power. 
In contrast, it has at least become clear that the scope of human rights is limited and that social work tends to stand in the shadow of the globalized world. As a human rights profession, it cannot enforce the law, but "only" to a limited extent it can promote the exercise of rights.

That means, the only capability the profession has at its disposal in terms of power is to inspire a critical discourse in the contested political space. Reflective deepening is desirable on this point as well. Politics in the global society and the politics of human rights would be mentioned as two variants of how to understand politics. The exercise of rights takes place in social spaces that are constantly being remeasured. But the political dimension cannot simply be juxtaposed with this situation. M. Foucault's notion of governmentality expresses the difficulties of political analysis (Foucault 2006). Political power is embodied in institutions and procedures, calculation and tactics, forms of knowledge and economics. However, the population is not simply the object of this power formation; it is in many ways intertwined with the techniques of governance. This affects social work as well - it is part of the governance complex by which the state indirectly directs and influences the actions of state, social, and civic actors as well. Government from a distance channels "global social policy" - and the helping professions recognize themselves as part of this power dispositif.

What needs to be addressed first, then, is deepening insight into the limits of one's discipline. For nothing leads past the insight into the manifold entanglements in power and dependency relations (Graßhoff/Homfeld/Schröer 2016, pp. 49-68).

This insight into one's own limitations is not new. But the conditions under which politics and domination exist are continually changing. The "politics of human rights" is not in itself a fixed but a flexible construct. It evolves, increases, at least semantically - and must always accept setbacks.

In the following, let us consider one area in which the value of social pedagogical discourse can be demonstrated: orientation to human rights. Human rights issues prove intrusive in a number of ways. They are to be considered in the context of those global problems that cannot be dealt with by conventional political concepts. They call into question the self-evident things that have been handed down and challenge new forms of organization in social relations. What they have in common is a peculiar distance from the linear success stories that are generally preferred.

A "success" is evident in the influence of a political public sphere that exposes social grievances; a success might be the expansion of civil society projects that gradually prevail over all warlike forms. Success, finally, would also be seen in the spread of an inclusive education that leaves no one out.

Can such successes also be "claimed" in a global context in which we are dealing with permanent violence, existential crises and social inequality? In other words, would not the reference to a progressive recognition of global values be "blind" to the unavoidable fossilizations of international politics? The answers will vary. Here, at least, an outlook will be ventured in the following, linking the key issues of the 21 st century with the profile of international social work. The enabling of peace in the horizon of suffered violence is to be taken up as a theme - and it is to be asked how it conditions the framework of a theory of social work that has to assert its own position in the midst of global interdependence. 


\subsection{The Politics of Human Rights}

Human rights are not an abstract construct. It is in the course of a concrete confrontation with a "case" or a situation that they acquire their actual significance. Only in the friction with people's social reality do they become tangible and vivid. The following "story" can be used as an example.

"A young man from Syria is picked up by the police and taken into care by the public youth welfare organization. He tells the professionals of the locally responsible youth welfare office that his parents are deceased, but that there are probably family members in Sweden." (Rölke/Bauer 2018, p. 212)

In complex modern societies, law has a special significance. Human rights push for realization. The violation of rights is tantamount to a scandal that alarms various interest and professional groups. When it comes to children's rights, however, the goal must be to find a remedy quickly, to find solutions. This concerns the self-image of social work in particular - as a human rights profession, it takes sides with those whose rights are threatened.

However, the example also shows that it is about social events for which no social and societal power alone is responsible and which can only ever be considered in a thicket of different areas of validity. The "analysis" of a biography marked by war and violence cannot simply be transferred into a position of self-empowerment. In the fissured spaces of transmigration, war, as currently in Syria, remains a subject and a condition. It turns out that the unconditional primacy of respect for human and children's rights has a dignity, an intrinsic value. But law itself is just a functional system: it provides distinctions and semantic certainties. But it cannot guarantee the smooth realization of rights.

This quasi-trivial insight concerns a sensitive core of social work. As a social "actor", it sees itself under the obligation to point out grievances and to promote the right of everyone by appropriate means. The right should not remain a mere postulate, but should be granted in practice. This obligation, which is expressed on the ground in advocacy, rests on a universalist foundation that can be recognized in international pronouncements (Ross/Knecht 2018, p. 332).

But it is left as an almost impossible task to people on the ground to bring the principled tension between violence suffered and the granting of rights into a livable relationship. This work is not to be understood as the realization of an unfulfilled claim, but as the cooperative shaping of a life-serving perspective.

However, this does not mean accepting the violation of rights and understanding the obvious injustices as a factual condition. Rather, the question is how to advance the politics of human rights in the globalized world. And on this point, at least, one can claim progress in global rights development. It begins with the perceptible human rights sensitivity that is leaving its mark worldwide. In almost all global questions of human rights, moralizing appeals prove to be an expression of an increased human rights culture. As is so often the case, progress has an unmistakable ambivalence - for reference to violated rights can always be used as an ideological weapon or as camouflage for particular interests. Moreover, the distance between positive law and purely moral legitimation must always be kept in mind: for problematic remain those legitimations that lack the characteristic of democratic consent.

Despite all skepticism, can we claim progress in the international dimensions of politics that will ultimately prove beneficial to social work practice? In this context, sociologist Hauke Brunkhorst speaks with good reason of a "strong world public sphere in the making" (Brunkhorst 2003, p. 71). 
The current world public sphere is to be understood as a weak public sphere with strong rights. The existence of a system of hard human rights in a hegemonically shaped world is one side - the other side is the perspective of a transnational, global public sphere that has mastered both the moral and legal language of human rights.

Evidence of the efficacy of the global public sphere can be drawn upon. Optimistically formulated, a global people is forming whose weak legitimacy is compensated for by the openness of the discussions. The colorful mixture of "NGOs, selfhelp groups, international trade unions and citizens' movements, social protest groups and human rights groups participate in the formation of the will of a global people" (Brunkhorst 2003, p. 83).

Its legitimation is a new, civil society culture of resistance against undemocratic rule. And this is where the legitimate space of social work would be located, a space of constant disquiet that helps to give validity and voice to the unheard voices.

So what is it about the purported human rights culture of our time - do these rights possess the unconditional primacy over all state rule and thus provide the framework, the ultimate basis of human interaction? So one could argue - and one could insist, moreover, that social work plays an essential part in ensuring that these rights are respected.

A differentiation is nevertheless in order. The social work profession has a global reach: it attends to the concerns of downtrodden people worldwide. This self-description of advocacy is not a hollow phrase, but a necessity. However, human rights work itself needs to be looked at in a more nuanced way.

For what does it mean to promote human rights? Since the Declaration of Human Rights 1948, we have been able to invoke an inalienable component of international law and to the same extent we have to take note of politically motivated violence, exclusion and breaches of the peace (Wevelsiep 2008, Ders. 2009, Ders. 2011). This gap cannot simply be bridged. Rather, such politics, the excesses of which have been seen enough in international relations, sooner or later result in disregard for the foundations of international law.

Moreover, while law itself is universalistic - it excludes no one - it is not subject to absolute "equality of meaning" (Graßhoff et. al. 2016, p. 108). World law is not a monolith, but a multi-layered shape; it recognizes different legal traditions, obligations, and ideas embedded in the particular history of a region.

What is the role of international social work in this society with a strong world public sphere on the rise? As forceful as the reference to globally applicable norms and rights may be, social work practice itself is challenging. It consists primarily in dealing with crisis situations; it deals with problematic situations that arise as a result of oppression, exclusion, threats, and violations. One might conclude that this is existentially urgent aid, which in a sense has police and developmental qualities. But it is not without reason that a "change in the politics of helping" is called for in this context (Ibid., p. 109).

On trial are the conventional principles of human rights work in the shadow of modernity. The relationship to the state is to be changed - social work is precisely not to be understood as an executive organ of the state. Social work is critical of all state authority and at the same time oriented towards pre-state human rights. In this respect, it needs independent visions of the good life in the fractured regions of the world. It is partisan work for the weakest, but at the same time it must recognize that advocacy for disadvantaged groups is expressed at different levels. The protection of children's rights, for example, is an absolute priority, but this also means that children can act as subjects and as representatives of their own interests. Even in situations of catastrophic proportions, in which the suffering of children is shown in all its urgency, a right to be heard, for 
example, would also have to be observed here. Children are to be taken seriously - just as all people in regions remote from the state are not to be regarded as objects of an enforcement practice (Maaser 2010. p. 49; Nikku 2012).

\section{Conclusion}

The example shows how ultimately contradictory the aforementioned discourse remains - it does not take a clear position, nor does it "deliver" any robust statements. The connection of fundamentally separate levels is its genuine core: it begins with the skeptical insight that the world is not in harmony and that we are referred to the practice of misfitting beings.

Of course, there are good reasons to argue that it is incumbent upon social work to look for solutions in conflicts, by means that must be non-violent. Language seems to offer itself as the only effective medium to confront violence with a claim to non-violence. But how we ultimately understand this confrontation is not indifferent: for it is not a matter of islands of nonviolence to which we can take refuge. Rather, it is about creating free spaces of renouncing violence in a common world in which violence always already exists and which is never free of power. Free spaces and living worlds, which, however, should ultimately prove to be life-serving.

\section{References}

Axel Honneth: Critique of Power. Reflection stages of a critical social theory. Frankfurt: Suhrkamp 1989

Christian Wevelsiep: Strong World Publics in the Making? Problems of world domestic politics using the example of Darfur. In: tabula rasa. Journal of Critical Thinking, 31, 1,2008

Ders. Climate Wars. What is being killed for in the 21st century. Frankfurt: S. Fischer 2008

Ders. Political philosophy after Rwanda - political conditions of "legitimate authority. In: journal of diaspora and genocide studies, vol. 2, 2009, pp. 88-111

Ders. The post-heroic society and its friends - on the argument of the limited willingness of modern societies to intervene. In: Journal of Foreign and Security Policy 2/2011, pp. 241-263.

Dieter Gosewinkel (ed.) Civil society. National and transnational. Berlin: Edition Sigma 2004

Frank Wilderson: Afropessimism. New York: Liverright Publishing Corporation 2020

Friso Ross/Matthias Knecht: Universal human rights protection and regional human rights instruments. In: Wagner/Lutz/Rehklau/Ross 2018, pp. 332-348.

Günther Graßhoff/Hans Günther Homfeld/Wolfgang Schröer: International Social Work. Cross-border linkages, global challenges and transnational perspectives. Weinheim/Basel: Beltz Juventa 2016.

Hans Joas: The Sacrality of the Person. A new genealogy of human rights. Berlin: Suhrkamp 2015

Hans Küng/Dieter Senghaas (eds.): Politics of Peace. Ethical foundations of international relations. Munich/Zurich: Piper 2003

Harald Welzer: Perpetrators. How ordinary people become mass murderers. Frankfurt 2005

Hauke Brunkhorst: Solidarity. Frankfurt: Suhrkamp 2002 
Hauke Brunkhorst: Politics on hunman rights. On the Constitution of World Society. Armin Nassehi/Markus Schröder (eds.): The Concept of the Political. Baden Baden: Nomos 2003, pp. 71-89.

Heinrich Geiselberger (ed.): The Great Regression. An international debate on the intellectual situation of the time. Berlin: Suhrkamp 2017

Jean-Luc Nancy. The unrepresentable community. Stuttgart 1988

Jürgen Habermas: The Inclusion of the Other. Studies in political theory. Frankfurt am Main: Suhrkamp 1996, pp. 11-65.

Magnus Frampton: European and International Social Work. A Textbook. Weinheim/ Basel: Beltz Juventa 2019.

Mathias Albert/Rudolf Stichweh (eds.): Welt-States. Observations on global political structure formation. Wiesbaden VS 2007

Michel Foucault: History of Governmentality: Security, Territory, Population. Lecture at the College de France 1977-19978. Translated from the French by C. BredeKonersmann and Jürgen Schröder. Frankfurt: Suhrkamp 2006

Nikku, B. R.: Children`s rights in disasters: concerns for social work - insights from South Asia and possible lessons for Africa. In: International Social Work 56, issue 1, pp. 51-66, 2012

Steven Pinker: Violence. A new history of humanity. Frankfurt am Main: Fischer 2013, p. 125.

Thorsten Bonacker: The Community of Deconstruction. On the Normative Content of Liberal Community. In: Andrea Kern/Christoph Menke (eds.) Philosophy of Deconstruction. Frankfurt: Suhrkamp 2002, pp. 264-289.

Ursula Rölke/Marc Bauer: Overcoming Borders - Protecting Children - Connecting Families. International social work as cross-border individual case work in the interest of children and young people. In: Leonie Wagner/Ronald Lutz/Christine Rehklau/Friso Ross (Hg.): International social work. Weinheim/Basel: Beltz Juventa 2018, pp. 209-227

Wilson, J. Q.: Thinking about crime. New York: Basic books 1974

Wilson, J. Q. /Herrnstein, R. J.: Crime and human nature. New York: Simon and Schuster 1985

Wolfgang Maaser: Ethics. Foundations, problem areas and perspectives. Weinheim: Juventa 2010 